\title{
Habitat mapping and conservation threats to river dolphin in Karnali River of Nepal
}

\begin{abstract}
R. Malla ${ }^{1}$
This study was carried out in the Karnali River of Nepal with the aims of preparing habitat map of dolphins in the Karnali River and assessing conservation threats to dolphin at the local level. The habitat map of the dolphin was prepared on the basis of study and local sightings. Altogether 100 households were surveyed around the Karnali River living within $3 \mathrm{~km}$ from the river distance. Questionnaire survey, group discussion, field observation and key-informants interviews were conducted to assess conservation threats to dolphin at the local level. Statistical tools like Pie chart and bar diagram were used to analyze the data. Use of poison in the river, commercial and domestic consumption of fishes, and high dependency of people in the river are emerging as the threats to dolphin conservation. Similarly, the increasing trend of using chemical fertilizer in the agriculture land is also adding up to long term negative impacts on dolphin population. Regular habitat monitoring of the dolphins should be done in major areas to acquire timely information on status and distribution of dolphins for dolphin conservation. Also, local people should be provided with alternate incentives by actively mobilizing them in dolphin conservation work
\end{abstract}

Key words: Dolphins, habitat mapping, conservation threats, Karnali river

D olphins were once abundant in Nepal throughout the Koshi, Narayani, Karnali and Mahakali Rivers and their feeder streams (Jnawali and Bhuju 2000). Due to construction of low gated dams across river systems for irrigation and flood control, over exploitation of prey species, illegal killing and a wide range of other human disturbances, the populations are now more or less restricted to Karnali and Koshi River systems (Smith 1993). The only river in Nepal that perhaps supports a viable population is the Karnali, upstream of the Girijapur barrage, but this population may become extinct in the absence of conservation action on both sides of the Nepal/India border (Smith 1996).

Dolphins are particularly threatened in the upstream reaches of the smaller tributaries, where populations are often isolated behind barrages and are more vulnerable to human activities because of the reduced habitat area and perhaps the most endangered populations are in Nepal (Sinha et al 2000). For Nepal, Smith et al (1996) summarized that in the Karnali and Narayani River basins aquatic species are threatened with local extinction from the effects of habitat degradation, segregation of breeding groups by down stream barrages, incidental catches during fishing operations and declines in prey fish populations. Sinha et al. (2000) warn that the most threatened populations are those of Nepal, with the only remnant groups in the Karnali and Koshi Rivers. Timilsina (1999) also reported that human disturbances like over fishing, harmful fishing techniques, motorized transport, rock mining, removal of woody debris, channelization etc were the problems facing the dolphin, along with these lack of conservation awareness among the people and not much emphasis by the park authorities add to the problem.

\section{Materials and methods}

Selection of the study area and respondents

The study area was selected on the basis of distance i.e. up to $3 \mathrm{~km}$ from the river vicinity. People living within $3 \mathrm{~km}$ from the river distance were surveyed randomly. Altogether one hundred households were selected for the study from different areas i.e. Gola, Manau, Kothiaghat, Suryapatuwa, Pashupatinagar, Shivapur, Khairichandrapur and Guptipur.

\section{Reconnaissance survey}

Preliminary survey was conducted prior to initiation of the detailed field survey to identify potential habitats of dolphins in the study area. The preliminary survey was then followed by detailed field survey.

\footnotetext{
${ }^{1}$ Asst. Research Officer, Department of Forest Research and Survey, Kathmandu. E-mail: raj_malla@yahoo.com
} 


\section{Detailed Field survey}

Highly potential area for the dolphins was identified through Participatory Rural Appraisal (PRA) tool such as participatory resource mapping and interview with key informants. Getting idea on potential habitat of dolphin, field survey was carried out in October, 2006 (Post monsoon) along the Geruwa River (tributary of Karnali river) using raft. The raft was halted for 15- 25 minutes in highly potential areas. Surfacing of dolphins was observed and the coordinates of the sighted points were marked by GPS. These coordinates were then transferred to Topo-maps of the study area and digitization was done thereafter. Finally, using Arc View GIS 3.1 version software, the habitat map of dolphin in Karnali River was prepared on the basis of both local sightings ${ }^{1}$ and study sightings ${ }^{2}$.

\section{Questionnaire survey}

A set of semi-structured questionnaire was used as a tool to collect primary data in order to achieve the research objectives. The questionnaire contains two parts. First part includes socio-economic condition of the respondents and conservation threats prevailing in the study area. Second part includes different statements to gauge the perceptions of the people on different aspects of dolphins. Different categories of the respondents (i.e. by sex, distance and caste) were used for the conservation threats analysis and perception of people more accurately. The perception of different levels of respondents was measured in a strongly disagree to strongly agree (1-5) Likert Scale. The questionnaire was prepared in English first and then translated into Nepali before the respondents were asked in the study area.

\section{Key informants Interview}

Informal interview was made with different key respondents like Village Development Committee chairman, Bardia National Park office staffs, NonGovernmental Staffs in order to get information on potential habitat of dolphins and its conservation threats at the local level.

\section{Group discussion}

Informal group discussion was conducted in the study area to acquire a rapid view of local people. Female participants and disadvantaged groups were encouraged to take part in the discussion and to offer their opinion on related matter.

\section{Direct observation}

Direct observation was also done in the study area in order to understand people pressure on the river for their daily needs. People involved in activities like fishing, collecting and transporting forest products, washing and bathing were observed in the study area. This method helped to verify data offer by the respondents during questionnaire survey and informal discussion.

\section{Secondary data collection}

Secondary data were collected from official records of Bardia National Park Office, Bardia Conservation Project (BCP) Office, Participatory Conservation Program (PCP) Office, WWF-Nepal and other related publications.

\section{Data analysis}

Analysis of the final habitat map of the dolphin in Karnali River was done using Arc-View GIS 3.1 software. All socio-economic data were categorised first in three categories, i.e. Sex, Caste and Distance. Within Sex; male and female; within Caste; ethnic and non-ethnic; and within Distance; near ${ }^{3}$ and far $^{4}$ sub-categories were made. Based on these categories, conservation threats to dolphin conservation at the local level were analysed using descriptive statistical tools like percentage, bar diagram and pie chart.

\section{Results and discussion}

\section{Habitat of dolphins}

The Dolphins were observed in the $20 \mathrm{~km}$ stretch of Karnali River from Golaghat to Kothiaghat during study period (i.e. post monsoon). They were sighted very often at Golaghat, Bindrabahi, Saijanaghat and Kothiaghat. The channel width and depth of sighted spots ranged from $100-150 \mathrm{~m}$ and 5-15 m respectively. These spots are regarded as primary habitats of dolphins during winter season. But, according to the people, they were also sighted at Lalmatighat, Sonahaphant, Manaughat and Orai dovan.

Shrestha (1989) observed dolphins within a range of $46 \mathrm{~km}$ during his survey in 1982 and 1983. Shrestha

\footnotetext{
${ }^{1}$ Dolphin sighted by local people in the study area

${ }^{2}$ Dolphin sighted during study period in the study area by the researcher

${ }^{3}$ Within $1 \mathrm{~km}$ distance from the river

${ }^{4} 1$ to $<3 \mathrm{~km}$ distance from the river
} 


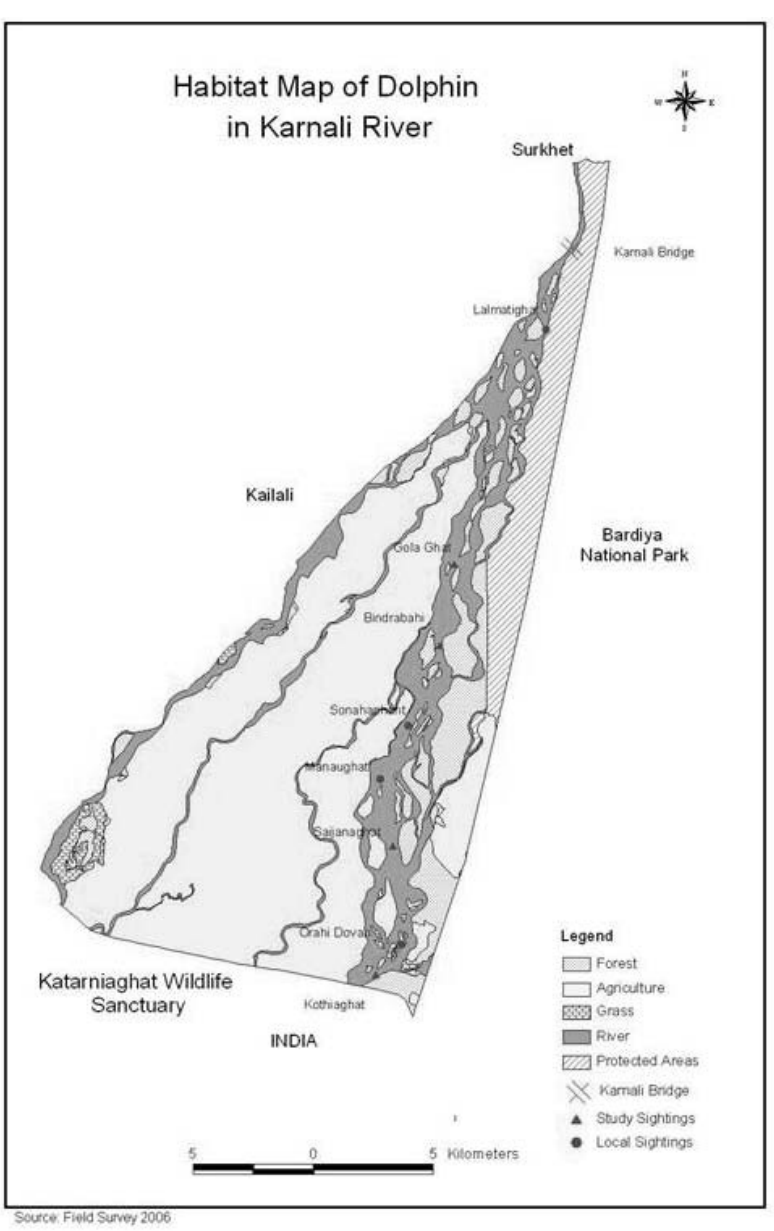

(1995) during his survey in 1986 sighted dolphins in the same range. Smith (1993) during his survey of 1990 observed within a range of $18 \mathrm{~km}$ from Kothiaghat as compared to previous distribution range of $46 \mathrm{~km}$. Similarly, Smith (1994) during his survey of 1993 observed dolphins within a range of $20 \mathrm{~km}$ from Kothiaghat to Golaghat. Shrestha (1995) sighted these animals with a comparatively increased range of $36 \mathrm{~km}$ from Kothiaghat during his surveys in 1994 and 1995. Timilsina (1999) sighted dolphins in the range of $17 \mathrm{~km}$ and identified primary habitats of dolphins where the convergent streams create an eddy counter current system whereas marginal habitat had low or no eddy counter current.

\section{Socio-economic condition of the people}

\section{Population by Caste}

All castes have been categorized into two main categories for the study. One is Ethnic (it includes Chaudhary, Thapa, Gurung etc) and other is Nonethnic (it includes Brahman, Chettri, Thakuri). Majority of respondents were from ethnic group. Mainly, people from "Tharus" caste are the dominant majority, with 38 percent and are indigenous to the area
Family size

The average family size was found to be 8.7 numbers per household in the study area with minimum of 3 , maximum of 21 and standard deviation of 3.41. Average family size in the study area was larger than average family size of the country i.e.5.4 (CBS, 2003).

\section{Education Level}

The education level of the respondents was categorized into four groups i.e. Illiterate, Primary level, Lower secondary and Secondary level and Higher secondary level. Of the total, majority of the respondents (55\%) were from 'Lower secondary and secondary level' in the study area, followed by both Illiterate and Primary level and lastly by Higher secondary level with $16 \%$ and $11 \%$, respectively.

\section{Occupation}

The occupation of the people was mainly divided into two categories i.e. Agriculture and Nonagriculture High majority of people $(95 \%)$ were involved in agriculture for their livelihood. Remaining five percent people were running their livelihood in other ways. Dependency on agriculture is very high in the study area.

\section{Involvement of people in fishing activities}

Of the total households, 52 percent were involved in fishing activities and the rests were not involved. Majority of the people depend on fishing for their livelihood.

Indigenous Tharu and Sonaha communities have majority in the area and are involved in intensive fishing due to their fishing skills and lifestyle. Fishing is one of the major sources of income for these communities. Thus, fishing is an indispensable part of their lifestyle.

\section{People involved in fishing activities by "Distance"}

More than $58 \%$ of the total people living close (within $1 \mathrm{~km}$ from the river) to the river were involved in fishing activities. Only $41 \%$ people were not involved. Unlikely, only $35.71 \%$ of the total people living far (beyond $1 \mathrm{~km}$ from the river) were involved in fishing activities. The remaining $64.29 \%$ were not involved. It shows that majority of people living close to the river are dependent on fishing for their daily needs and it is just opposite in case of people living far. 
As a result, intensity of people involved in fishing activities is higher in the area within $1 \mathrm{~km}$. from the river than that beyond $1 \mathrm{~km}$. It means that as home distance from the river increases, intensity of people involved in fishing activities decreases and vice versa.

\section{People involved in fishing activities by "Sex"}

Of the total respondents, 51.56 and 52.77 percent people from male and female, respectively, were involved in fishing activities for their daily needs. Slightly over half of the male and female populations are involved in fishing activities.

The involvement of the male respondents and the female respondents in fishing is almost equal. It shows that the male and female are equally involved in fishing activities to run their livelihood.

\section{People involved in fishing activities by "Caste"}

Of the total respondents, 73.68 and 25.58 percent people from ethnic and non-ethnic categories respectively were involved in fishing activities for their daily needs. It shows that majority of people belonging to ethnic group are dependent on fishing for their daily needs and it is just opposite in case of non-ethnic.

Since, majority of people in the area belonging to Tharu and Sonaha communities (Ethnic caste), these communities are heavily engaged in fishing activities because of their fishing skills, lifestyle and poor socioeconomic condition since earlier times. Other communities arrived after successful eradication of malaria in 1950's. They have now settled and deforested virtually all land above the flood plain, except for the area incorporated within the national park (Smith, 1993).

\section{People involved in fishing by Sex, Caste and Distance}

Analyzing all categories of people involved in fishing activities, it was found that a high majority of the people engaged in fishing are from the male and female representing ethnic caste and living within 1 $\mathrm{km}$ from the river (i.e. MEW and FEW). Whereas, none of the people engaged in fishing are from the female representing non-ethnic caste and living outside $1 \mathrm{~km}$ from the river (i.e. FNM).

Where,

$\mathrm{FEW}=$ female, ethnic caste, living within $1 \mathrm{~km}$, $\mathrm{MNW}=$ male, non-ethnic, living within $1 \mathrm{~km}, \mathrm{MEW}$
$=$ male, ethnic, living within $1 \mathrm{~km}, \mathrm{FNW}=$ female, non-ethnic, living within $1 \mathrm{~km}, \mathrm{MNM}=$ male, nonethnic, living within $1 \mathrm{~km}, \mathrm{FEM}=$ female, ethnic, living outside $1 \mathrm{~km}$ to $<3 \mathrm{~km}, \mathrm{MEM}=$ male, ethnic, living outside $1 \mathrm{~km}$ to $<3 \mathrm{~km}$ and $\mathrm{FNM}=$ female, non-ethnic caste, living outside $1 \mathrm{~km}$ to $<3 \mathrm{~km}$

\section{Purpose of going to the river}

People used to go to the river for different purposes such as fishing, washing and bathing, livestock wallowing and firewood transportation. The majority of the people in the study area go to the river for fishing, bathing, washing and their livestock wallowing. More than thirteen percent people go to river for transportation of firewood, which they collect from the national park area.

These anthropogenic factors affect aquatic lives in long run by degrading their habitat quality.

\section{Purpose of fishing}

People do fishing for different purposes such as domestic use and commercial use. It is categorized into 3 categories i.e. Domestic use, Commercial use and both Domestic use and Commercial use. Of the total, 65.3 percent people do fishing only for domestic use followed by domestic use and commercial use $(26.9 \%)$ and only commercial use (7.69\%).

It shows that most of the people in the area are involved in fishing at the subsistence level. Domestic consumption of fishes is high in the area because of lack of alternate opportunities. Killing of fishes for both domestic and commercial use is becoming a major threat of dolphin conservation as it highly contributes to the depletion of prey availability for dolphin.

\section{Methods of fishing}

The local people around the Karnali River use different methods of fishing. They use poison and other means like cast nets, gill nets and hook line for fishing. Of the total households involved in fishing activities, 32.6 percent use poison and 67.4 percent use other means.

The use of poison degrades water quality and kills large number of fishes and other aquatic faunal species as well. As a result, it causes depletion of prey availability and degradation of habitat quality of dolphins. Besides the use of poison, gillnets also causes havoc to the dolphin population because 
dolphins fail to echolocate the nets and while trying to catch fishes, they were trapped in such nets, usually the young ones get entangled and drown. It is highly destructive as it accidentally entangles all size of fish fauna and thus poses a dire threat to breeding fish populations. Cambodian Mekong Dolphin Conservation Project in 2004 reported 14 mortalities of Irrawaddy River dolphin as a result of gillnet entanglement (WWF Proceedings, May 2006). Joshi (2004) also reported the use of hook line became cause of entanglement and death of a calf dolphin in Mohana River.

\section{Income from sale of fish}

The local people in the study area earn money through sale of fish to run their livelihood. They often sell fish nearby the market like Thakurdwara, Chisapani, Kothiaghat etc. Their earnings have been put into 3 categories for the study i.e. less then Rs.2000/month, Rs 2000 to $<6000 /$ month and Rs. 6000 to $<9000 /$ month. Majority of people earns Rs. 2000 to $<6000 /$ month.

Selling of fish is one of the major sources of income for the local people. At the same time, it is one of the major threats of dolphin conservation because of depleting prey availability for dolphins.

\section{Time spent in river dependent activities}

The local people spend few to several hours in the river for their daily activities. Altogether, 4 categories have been made for the study i.e. occasionally, $<5$ $\mathrm{hr} /$ day, 5 to $<10 \mathrm{hr} /$ day and $>10 \mathrm{hr} /$ day. The majority of the people spend less than $5 \mathrm{hrs}$ per day for their daily activities.

Involvement of the people in the river dependent activities like fishing, bathing, washing, taking livestock wallowing, firewood transportation and motorized boat directly affect the freshwater faunal species. Human disturbances are becoming a cause of depletion of dolphin population in the river. Dolphins had not been seen in former habitat areas above Chisapani since the introduction of motorized boat in 1986 (Shrestha 1995). And, review of secondary sources also shows a steep decline in population of dolphins after the introduction of motorized ferry at Kothiaghat.

\section{Use of fertilizer in agriculture land}

The majority of the people (57\%) living around the river are using chemical fertilizer in their farmland.
Many people have also done agriculture practice in land adjacent to riverbank. The trend of using chemical fertilizers is rising to increase agricultural productivity. So leaching of chemicals to the river through agriculture run off probably exists. The close proximity of surviving pockets of dolphins to the agriculture land makes dolphins vulnerable to poisoning by toxic chemicals from these sources. These agrochemicals also harm dolphins both directly and indirectly through the food chain (Behera, 2005).

\section{Conclusions}

After the monsoon, the water level of Karnali River drops low. As a result, dolphins are mostly confined to the area where channel width and depth are high. Golaghat, Saijanaghat, Bindrabahi and Kothiaghat are the major spots of dolphin during winter period along Geruwa River. Lalmatighat, Manaughat, Orai dovan, Sonahaphant are also the potential habitat for dolphins based on local sightings.

Anthropogenic activities like fishing, washing, transporting forest products and livestock wallowing are the major river dependent activities being done by the people. The people used to spend lots of time in river dependent activities for their livelihood. They are becoming major threats to dolphin conservation as such activities create gradual disturbances on aquatic ecosystem. Similarly, the trend of using chemical fertilizers around the river area is increasing and this will in turn pose great threat to dolphin conservation in long run.

Especially, the people living near (within $1 \mathrm{~km}$ ) to the river are the major stakeholders since they are creating heavy pressures on the river for their daily activities. Within them, particularly, the male stakeholders belonging to Ethnic caste are heavily engaged in fishing activities. The low economic condition, big family size and lack of alternate opportunities are the major causes of intensive fishing for both domestic and commercial purposes. The people are not very careful to choose harmless methods of fishing. They use whichever fishing tools are handy. The use of poison and gillnets are becoming major threats of dolphin conservation as these deplete prey availability of dolphin to a great extent and cause mortality of dolphins by degrading habitat quality and by accidental entanglement. 


\section{Recommendations}

- Frequent habitat monitoring of dolphins in the major spots should be done.

- The habitat map of dolphins in the different seasons should be prepared.

- Giving them alternate opportunities i.e. making fishing pond, providing skill and employment should gradually reduce the dependency of the people on the river.

- The trend of using much chemical fertilizer on the agriculture land (which is close to the river) should be discouraged and encourage people applying organic manure.

- The people belonging to the ethnic caste and living within $1 \mathrm{~km}$. distance from the river should be recognized as prime stakeholders during implementation of dolphin conservation activities.

- The awareness raising programs regarding dolphin conservation should be implemented in the area, close to the river, focusing on the people from the ethnic caste.

- NGOs and INGOs should work with the local people harmoniously in the dolphin conservation work.

\section{Future research}

- Intensity of chemical fertilizers being used in the area and its impact on water quality should be studied.

- Intensive fishing causes depletion of prey availability to dolphins. To reduce this pressure on dolphins, the breeding season of prey of dolphins should be identified in order to prescribe right season for fishing.

- Studies on dolphins, so far have been limited to status, distribution and conservations threats, further the study should focus on its ecological behavior and habitat suitability.

- Dolphin conservation and its impact on rural livelihood should also be a topic of study in future.

\section{Acknowledgements}

I would like to acknowledge my advisor Mr. Shree Prasad Dhaubhadel for his continuous guidance during entire study. Similarly, I am very thankful to Mr. Naresh Subedi, Mr. Omkar Joshi and Mr. Chiranjivi Pokharel for their generous support during field study.

\section{References}

Behera, S. K. 2005. Conservation of Ganges River Dolphin in upper Ganga River, Project Report, WWF India.

CBS. 2003. Statistical Pocket Book, Central Bureau of Statistics, Kathmandu, Nepal.

Jnawali, S.R. and Bhuju, U.R. 2000. The Ganges River Dolphin: Current status and conservation threats. A paper presented in WWF Regional Workshop on the South Asian RiverDolphins, 4-7 November, Taunsa, Pakistan.

Joshi, D. 2004. Status, Distribution and Management of River dolphin (Platanista gangetica) in Lowland Karnali. M.Sc. Thesis, Pokhara University, Nepal.

Shrestha, T.K. 1989. Biology, Status and Conservation of the Ganges River Dolphin in Nepal. pp70-76 in W.F. Perrin (ed), R.L. Brownell, Jr. Zhou Kaiya and Liu Jiankang . Occasional papers of IUCN/SSC, No.3.

Shrestha, T.K. 1995. The Ganges River Dolphin. Variety Printers, Kathmandu.

Shrestha, T.K. 1995. Fish Catching in the Himalayan Waters of Nepal. Kathmandu, Nepal. 247 pp.

Sinha, R.K. 2000. Status and Distribution of Ganges susu in the Ganges River System of India and Nepal. pp 54-60, in R.R.(ed) Reeves, B.D. Smith and T. Kasuya. Biology and Conservation of Fresh Water Cetacean in Asia, IUCN Species Survival Commission Occasional Papers No. 23

Smith, B. 1993. 1990. Status and Conservation of the Ganges River Dolphin (Platanista gangetica) in Karnali River, Nepal. Biological Conservation. 66:159-170

Smith, B. D., Sinha, R.K., Regmi U. and Sapkota K. 1994. Status of Ganges River Dolphin in Carnal, Mahakali, Narayani and Saptakosi Rivers of Nepal and India in 1993. Marine Mammal Science. 10:368375.

Smith, B., Bhandari, B. and Sapkota, K. 1996. Aquatic Biodiversity in the Carnal and Narayani River Basins. IUCN. 62pp

Timilsina, N. 1999. Present status and conservation of Gangetic dolphin in the Carnal River, Western Lowland of Nepal. M.Sc. Thesis. Tribhuwan University. Katmandu. 45pp

WWF. 2006. Conservation and management of river dolphins in Asia. Proceedings of the regional meeting, Kathmandu, Nepal. 27pp 